\title{
Adaptive filter-FLC integration for torque ripples minimization in PMSM using PSO
}

\author{
Yasser Ahmed ${ }^{1}$, Ayman Hoballah ${ }^{2}$ \\ ${ }^{1,2}$ Taif University, Saudi Arabia \\ ${ }^{1}$ Electronic Research Institute, Egypt \\ ${ }^{2}$ Tanta University, Egypt
}

\begin{tabular}{l}
\hline \hline Article Info \\
\hline Article history: \\
Received Jul 18, 2018 \\
Revised Oct 14, 2018 \\
Accepted Dec 3, 2018 \\
\hline
\end{tabular}

Keywords:

FLC

IIR filter

PMSM

PSO

Torque ripples minimization

\begin{abstract}
The article presents torque and flux ripples minimization based on adaptive filter. The adaptive filter coefficients optimized and adapted on line by using particle swarm optimization (PSO) technique. The proposed methodology applied on closed loop speed control based on direct torque control (DTC) for surface mounted permanent magnet synchronous motor (PMSM). Fuzzy logic controller (FLC) used as speed controller while proportional-integral (PI) controller used as torque and flux controllers. Second order infinite impulse response (IIR) filter is used for ripple reduction generated due to FLC. The drive system modeled using Matlab/Simulink software in order to dynamically evaluate the performance of the proposed drive system at different operating conditions. The results provide evidence that the adaptive filter-FLC integration with optimal coefficients minimizes torque and flux ripples with reduction of total harmonic distortion generated in the threephase currents.
\end{abstract}

Copyright (C) 2019 Institute of Advanced Engineering and Science. All rights reserved.

\section{Corresponding Author:}

Yasser Ahmed, Taif University, Saudi Arabia.

Email: abdelsalamyasser@yahoo.com

\section{INTRODUCTION}

One of the famous drive systems is permanent magnet synchronous motor (PMSM) that is used in the applications which require high-performance such as robotics, transportation and industry. The main advantages of PMSM are high efficiency, small losses, low motor size, high power density, high acceleration and deceleration. Speed of PMSM can be controlled by using either direct torque or field oriented control (DTC or FOC). The DTC is preferred because of its rapid dynamic torque response, simple structure and robust control scheme. However, DTC has drawbacks such as ripples in torque and flux, which cause considerable amount of noise and vibrations which affect the derive performance [1], [2].

There are two operating techniques of the DTC, space vector modulation (SVM-DTC) and conventional switching table (ST-DTC). In the SVM-DTC, arbitrary voltage vectors with variable magnitudes and fixed switching frequency are generated for controlling the torque and flux with less ripples that the SVM-DTC is more accurate than the ST-DTC. In order to control the torque and flux based on the ST-DTC, the appropriate voltage vector is pinpointed from switching table of a certain number of specified voltage vectors that are estimated at variable switching frequency. Therefore, the SVM-DTC is used in this work [3], [4].

The used methodologies for ripples minimization in the motor drives are optimal design of the machine and suitable control scheme. The design process should optimize the stator and rotor parameters to reduce the cogging torque as well as harmonic contents of the magnetic flux. Further study was in [5] in order to reduce the cogging torque where the proposal was based on the design of slots widths and tooth profiles. In [6], the author studied the combination influence of consideration of the pole and slot shapes on 
torque ripples in a PMSM and the results clarified that the ripples maybe increased if the machine is not carefully designed.

Many control methodologies have been reported in the literature for limiting flux and torque ripples in which it maintained smooth operation of the drive. The control methodology adapts the controller parameters to optimize the output voltage vector from the inverter [7], [8]. Toward the speed control using FOC in the interior PMSM drive system, [9] suggested to use the adaptive filter in order to minimize the torque ripples where the fuzzy logic controller (FLC) was designed and the filter coefficients selection was based on the trial-error concept. The speed harmonic magnitude is used as a feedback control signal in a closed-loop current controller in order to reduce torque ripples. The obtained results confirm the attained ripples reduction [10]. In [11], a modified switching table is designed for the three voltage vectors in DTC selection rather than two voltage vectors. The corresponding less ripple contents are ascertained in torque and flux with sinusoidal stator current. However, the durations of the three vectors are computed to reduce the switching frequency. In [12], variable amplitude and angle voltage vector have been controlled to reduce ripples based on DTC for PMSM drive system. A predictive DTC is proposed to enhance the conventional DTC performance during transient and steady state conditions. For fast transient response, a parameter regulation of the voltage vectors is considered. However, the ripples are minimized by investigating the optimal amplitude, angle, and duration of the voltage vector [13].

Artificial intelligence (AI) approaches were used for optimal selection of control scheme parameters to minimize torque and flux ripples and enhance system performance as reported in [14]. The famous examples of AI-based methods are genetic algorithm (GA) as well as particle swarm optimization (PSO).

In this work, the speed of surface mounted PMSM controlled using DTC technique. FLC integrated with second order infinite impulse response (IIR) filter used as speed controller while PI controllers used in torque and flux loops. The IIR filter used to reduce the ripples generated by FLC. PSO is used to optimize the system performance on-line by selecting the optimal coefficient of adaptive-IIR filter and controllers which minimize flux and torque ripples. The adaptive filter coefficients are optimized simultaneously and varied as a function in the torque ripples. A closed loop speed control based on FLC and SVM-DTC in surface mounted PMSM is proposed. The proposed system modelled in Matlab environment. The proposed method is justified by applying the methodology on different operating conditions of the system under investigation.

\section{TEST SYSTEM STRUCTURE}

The presented test system consists of PMSM with inverter bridge, speed FLC integrated with ripples minimization algorithm and DTC controller as depicted in Figure 1. The system components are as follows.

\subsection{PMSM mathematical model}

The PMSM model in rotating d-q frame is: [15], [16]:

$$
\begin{aligned}
& u_{d}=R_{s} \cdot i_{d}+\frac{d \psi_{d}}{d t}-w_{r} \psi_{q} \\
& u_{q}=R_{s} \cdot i_{q}+\frac{d \psi_{q}}{d t}+w_{r} \psi_{d} \\
& \psi_{d}=L_{d} \cdot i_{d}+\psi_{m} \\
& \psi_{q}=L_{q} \cdot i_{q} \\
& T_{e}=\frac{3}{2} P\left(\psi_{d} \cdot i_{q}-\psi_{q} \cdot i_{d}\right)
\end{aligned}
$$

From 3, 4 and 5, the electromagnetic torque $\left(T_{e}\right)$ can be derived as:

$$
T_{e}=\frac{3}{2} P\left(\psi_{m} \cdot i_{q}+\left(L_{d}-L_{q}\right) i_{q} \cdot i_{d}\right)
$$

From (6) shows that $T_{e}$ contains two components that are the torque due to permanent-magnet and the reluctance torque. For the PMSM type considered in the study, the surface mounted type has that $L_{d}=L_{q}$. This mean, the reluctance torque is eliminated, $T_{e}$ equation can be written as:

$$
T_{e}=\frac{3}{2} P \psi_{m} i_{q}
$$


$T_{e}=\frac{3}{2} \frac{1}{L s} P\left|\psi_{s}\right|\left|\psi_{m}\right| \sin \delta$

The mechanical equation of the PMSM can be formulated by [17]:

$$
T_{e}=T_{L}+J_{m} \frac{d w_{r}}{d t}+B_{m} w_{r}
$$

where $u_{d}, u_{q}, i_{d}$ and $i_{q}$ are stator voltages and currents respectively in d-q rotating frame. $R_{s}$ is the stator resistance. $w_{r}$ is the mechanical speed. $\psi_{d}, \psi_{q}, L_{d}$, and $L_{q}$ are stator flux and inductance components, respectively. $\psi_{s}$ and $\psi_{m}$ are the stator flux linkage and permanent magnetic flux, respectively. $\mathrm{P}$ is the motor pole pairs number. $\delta$ is the load angle. $T_{L}$ is the load torque. $B_{m}$ and $J_{m}$ are friction coefficient and composed motor-load inertia, respectively.

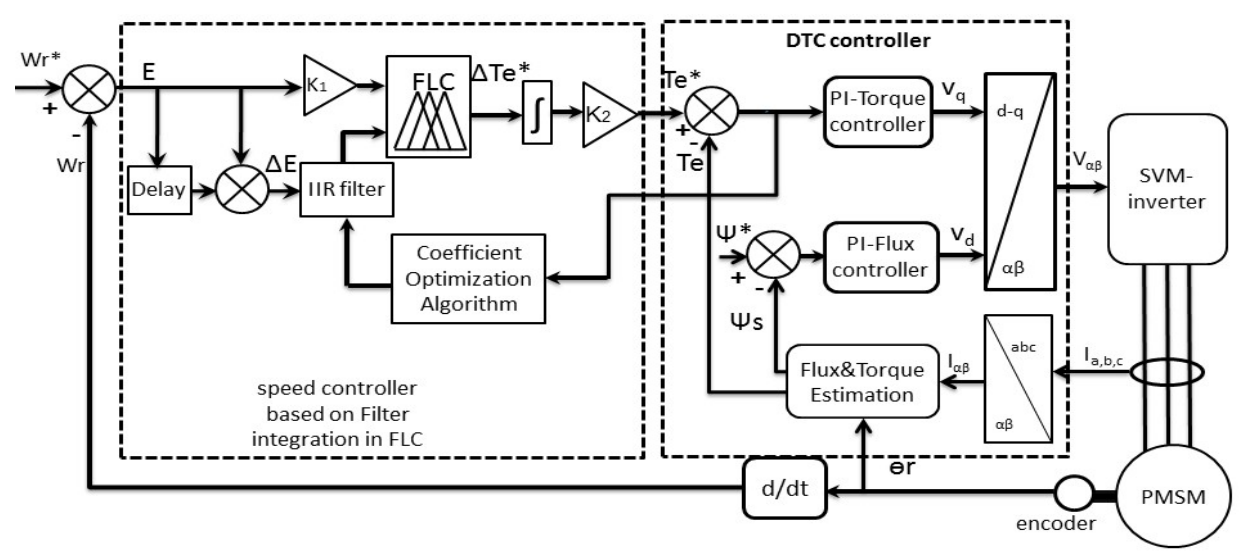

Figure 1. Test system structure

\subsection{Speed controller}

The FLC acts as a PI speed controller in the DTC drive system as depicted in Figure 1. By differentiation of 9 , the speed is regulated based on controlling the change in electromagnetic torque $\left(\Delta T_{e}^{*}\right)$ that is presented in (10). The components of speed controller explained in the following sections.

$$
\Delta T_{e}^{*}=\Delta T_{L}+J_{m} \frac{d \Delta w_{r}}{d t}+B_{m} \Delta w_{r}
$$

\subsubsection{FLC model}

The FLC consists of, fuzzification, fuzzy inference, and defuzzification as depicted in Figure 2. The speed error $(E)$ and its change $(\Delta E)$ are the FLC inputs while the torque change $\left(\Delta T_{e}^{*}\right)$ is the output. The inputs and output relationships of the FLC can be written as follows:

$$
\begin{aligned}
& E=w_{r}^{*}(n)-w_{r}(n) \\
& \Delta E=E(n)-E(n-1) \\
& \Delta T_{e}^{*}=f(\mathrm{E}, \Delta \mathrm{E})
\end{aligned}
$$

where $E(n-1)$ is a speed error pre-sample, $E(n), w_{r}^{*}(n)$ and $w_{r}(n)$ are the present samples of speed error, reference speed and mechanical motor speed respectively.

The fuzzification process maps the input variables $E$ and $\Delta E$ to the corresponding linguistic variables. The fuzzy inference gets the control rules for every input. The defuzzification converts the input rules to the crisp value of output $\Delta T_{\mathrm{e}}^{*}$.

Int J Pow Elec \& Dri Syst, Vol. 10, No. 1, March 2019 : 48 - 57 


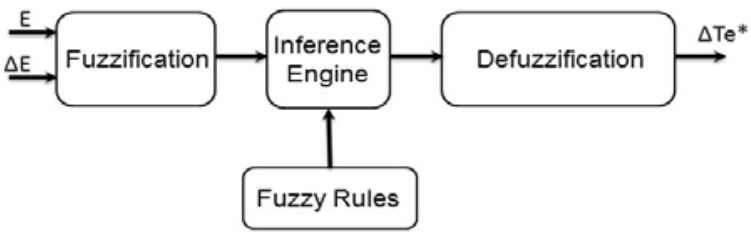

Figure 2. Fuzzy logic speed controller

The $E$ and $\Delta E$ membership functions are depicted in Figure 3(a). The designed sets of the input variables are as that $\mathrm{PB}, \mathrm{PS}, \mathrm{ZE}, \mathrm{NS}$, and $\mathrm{NB}$ are positive big, positive small, zero, negative small, and negative big, respectively. The output variable $\Delta T_{\mathrm{e}}^{*}$ membership functions are depicted in Figure 3(b) where the output sets are that PB, PM, PS, ZE, NS, NM, and NB are acronym of positive big, positive medium, positive small, zero, negative small, negative medium, and negative big, respectively. Membership types and limits are obtained by experience [18].

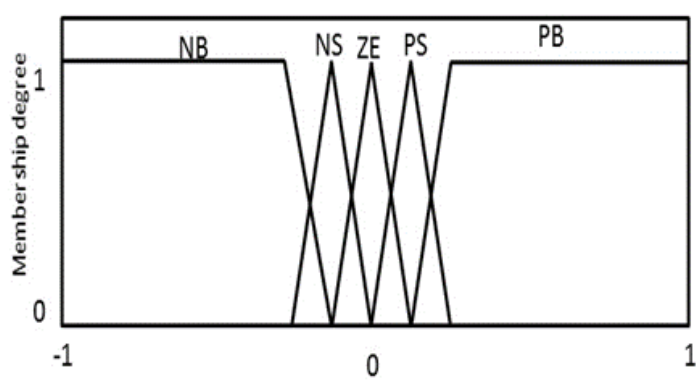

(a)

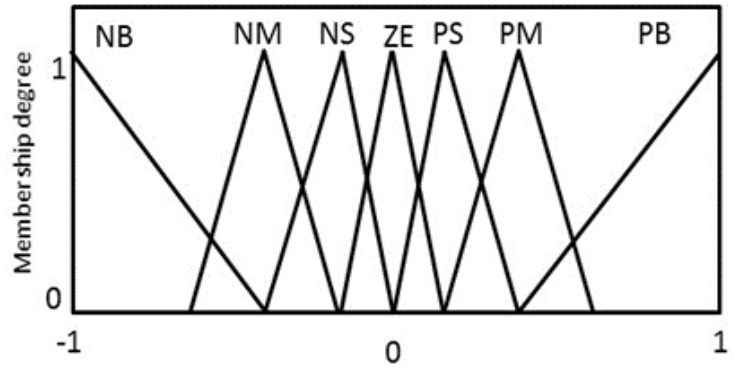

(b)

Figure 3. Membership of FLC

The fuzzy inference system uses Mamdani-type method where control rules of the fuzzy controller done by if and then logic operators according to the normalized values of $E$ and $\Delta E$ in order to estimate the set of $\Delta T_{e}^{*}$ as listed in Table 1 . The centroid method is used as the defuzzification method to compute the $\Delta T_{e}^{*}$ value to reduce the value of $E$.

Table 1. Fuzzy logic rules

\begin{tabular}{cccccc}
\hline$\frac{\Delta E}{E}$ & NB & NS & ZE & PS & PB \\
\hline NB & NB & NB & NB & NM & ZE \\
NS & NB & NM & NS & ZE & PM \\
ZE & NB & NS & ZE & PS & PB \\
PS & NM & ZE & PS & PM & PB \\
PB & ZE & PM & PB & PB & PB \\
\hline
\end{tabular}

\subsubsection{Ripples minimization algorithm}

The main source of speed and torque ripples in the proposed DTC system comes from FLC. 2nd order adaptive IIR filter utilized for ripples minimization. This proposed model is as illustrated in Figure 4 where it can be represented by the following time difference equation [19]:

$$
y[n]=a_{0} x[n]+a_{1} x[n-1]+a_{2} x[n-2]+b_{1} y[n-1]+b_{2} y[n-2]
$$

where $\mathrm{y}$ represents the filter output (filtered $\Delta E$ ), $\mathrm{x}$ represents the filter input $(E)$ and $\mathrm{n}$ represents the signal index. 
The filter coefficients are optimized using PSO algorithm to minimize the torque and flux ripple contents. Each filter coefficient can be represented by $a_{i}=k_{i}^{1}+k_{i}^{2} * \Delta T$, where $\Delta T=\left|\Delta \mathrm{T}_{\mathrm{e}}^{*}-T_{e}\right|$. The coefficients $k_{i}^{1}$ and $k_{i}^{2}$ are optimized simultaneously by PSO over all the operating points.

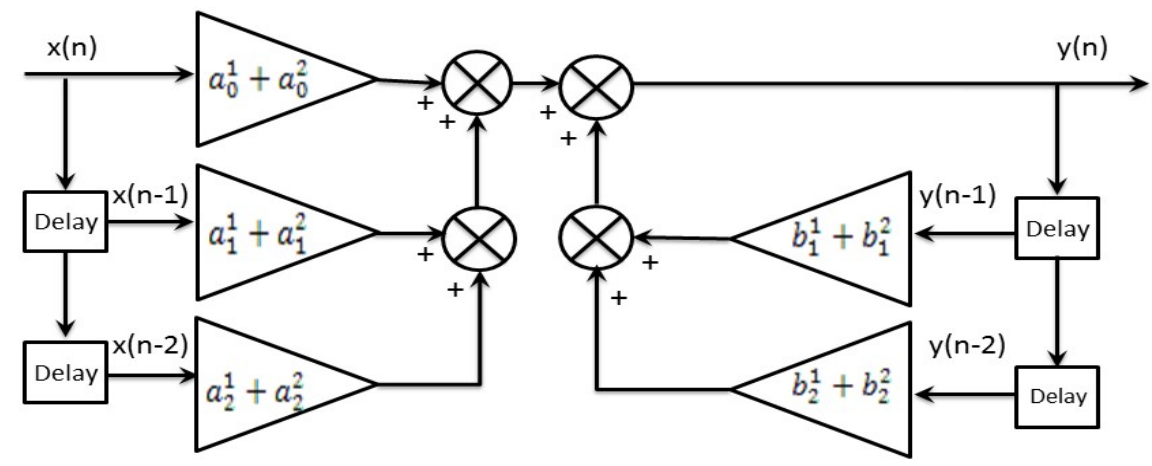

Figure 4. IIR filter model

\subsection{Direct torque control}

The voltage vector selection is the main key in the DTC, where a design of the voltage vector is made for the regulation of the electromagnetic torque and stator flux. From (8), the torque is a function in the $\delta$. The angle $\delta$ between $\psi_{s}$ and $\psi_{m}$ remains constant during steady state where both $\psi_{s}$ and $\psi_{m}$ run at the same speed. During transient state, $\delta$ is changed because of the rotation of both $\psi_{s}$ and $\psi_{m}$ at different speeds. Comparing with respect to electrical time constant, the system mechanical time constant is slower response, then the angle $\delta$ can be adjusted by regulation of the $\psi_{s}$ speed with respect to the $\psi_{m}$. This is implemented by selecting the suitable voltage vector for the error minimization of the torque and flux with respect to reference values. DTC block consists of PI-torque controller, PI-flux controller and flux/ torque estimator.

\subsubsection{Torque controllers}

The torque and flux controllers utilize conventional PI controllers. The input of the torque controller is the difference of the actual torque with respect to the reference value in order to attain the output $u_{q}$. The torque estimation is based on the measured current and estimated flux:

$$
T_{e}=\frac{3 P}{2}\left(\Psi_{\alpha} i_{\beta}-\Psi_{\beta} i_{\alpha}\right)
$$

\subsubsection{Flux controller}

The input of the flux controller is the difference between actual and reference fluxes while $u_{d}$ is the attained output. Then, the controllers output transformed to control voltage components in $\alpha-\beta$ frame $\left(u_{\alpha}, u_{\beta}\right)$ which are used to generate the SVPWM pulses that fire the inverter bridge. The generated voltage vector should maintain the torque and flux at its required value with minimum ripples. The magnitude and angle of $\Psi$ s can be estimated by the following equations [20].

$$
\begin{aligned}
& \Psi_{S}=\sqrt{\Psi_{\alpha}^{2}+\Psi_{\beta}^{2}} \\
& \theta_{S}=\tan ^{-1} \frac{\Psi_{\beta}}{\Psi_{\alpha}}
\end{aligned}
$$

where:

$$
\begin{aligned}
& \Psi_{\alpha}=\int u_{\alpha}-i_{\alpha} d t \\
& \Psi_{\beta}=\int u_{\beta}-i_{\beta} d t
\end{aligned}
$$


where $i_{\alpha}$ and $i_{\beta}$ represent the current components in $\alpha-\beta$ frame, $\Psi_{\alpha}$ and $\Psi_{\beta}$ represent the $\alpha-\beta$ components of the estimated $\Psi_{\mathrm{s}}$.

\section{PSO ALGORITHM}

PSO as one of meta-heuristic optimization techniques depends on searching the optimal solution within the search area based on the exchange of experiences among particles in the population. The particles in the swarm modify their positions in the next iteration based on individual local best position and global best position of swarm. Each particle represents a solution for the control variables of the entire optimization problem. The control variables which used for minimization of torque ripples in PMSM are the speed, flux, torque PI gains controllers and filter coefficients. For the particle (i), it modifies the position in the next iteration, $k+1,\left(P_{i}^{k+1}\right)$ based on the velocity $\left(S_{i}^{k+1}\right)$ of the particles using the following equations [21]:

$$
\begin{aligned}
& P_{i}^{k+1}=P_{i}^{k}+\chi S_{i}^{k+1} \\
& S_{i}^{k+1}=z^{k+1} S_{i}^{k}+C_{1}\left(S_{l i}^{k}-S_{i}^{k}\right)+C_{2}\left(S_{g}^{k}-S_{i}^{k}\right)
\end{aligned}
$$

where, $\chi$ is adaptive factor which used to control the swarm conversion. $\mathrm{z}$ is a weight factor for controlling the velocity of swarm towards the optimal solution. $\mathrm{C} 1$ and $\mathrm{C} 2$ are generated random numbers in the range of 0 and 2. $S_{l i}^{k}$ and $S_{g i}^{k}$ are the local and global best positions at the previous iterations.

The objective function is to minimize electromagnetic torque ripples $\left(T_{\text {ripple }}\right)$, which can be represented by the following expression:

$$
\begin{aligned}
& T_{\text {ripple }}=\sqrt{\frac{1}{n-1} \sum_{i=1}^{n}(T(i)-\bar{T})^{2}} \\
& \bar{T}=\frac{1}{n} \sum_{i=1}^{n} T(i)
\end{aligned}
$$

where $\mathrm{n}$ is the number of samples, $\bar{T}$ is the average value of electromagnetic torque.

The optimal solution should satisfy the operational constraints. The considered constraints are the stator flux ripples $\left(\Psi_{\text {ripple }}\right)$ and mean of speed error $(\bar{w})$ can be represented by the following expressions [22], [23].

$$
\begin{aligned}
& \Psi_{\text {ripple }}=\sqrt{\frac{1}{n} \sum_{i=1}^{n}(p h i(i)-\overline{p h l})^{2}} \\
& \overline{p h \imath}=\frac{1}{n} \sum_{i=1}^{n} p h i(i) \\
& \bar{w}=\frac{1}{n} \sum_{i=1}^{n} w(i)
\end{aligned}
$$

where, $\overline{p h l}$ is a stator flux average value.

The constraints are taking into account during optimization by an adaptive penalty function where a modified objective function formulated based on the normalized original objective function and normalized constraints violations [24], [20]. The modified objective function $\left(T_{\text {ripple, } i}^{\text {mod }}\right)$ which penalized the infeasible solutions for considering the constraints violations $\left(\mathrm{Vio}_{i, k}^{a v}\right)$ can be formulated by:

$$
T_{\text {ripple }, i}^{m o d}=\sqrt{\left(T_{i, k}^{n}\right)^{2}+\left(V_{i o}^{a v}\right)^{2}}+F_{i} * X+F_{f} * T_{i, k}^{n}
$$

Where $F_{f}$ and $F_{i}$ are the number of feasible and infeasible solutions in swarm respectively. $\mathrm{X}$ is penalization function which equal zero at no feasible solutions $\left(F_{f}=0\right)$ or $V i o_{i, k}^{a v}$ with no infeasible solutions $\left(F_{i}=0\right)$ in swarm at the entire iteration. The schematic diagram for the iterative process presented in Figure 5. 


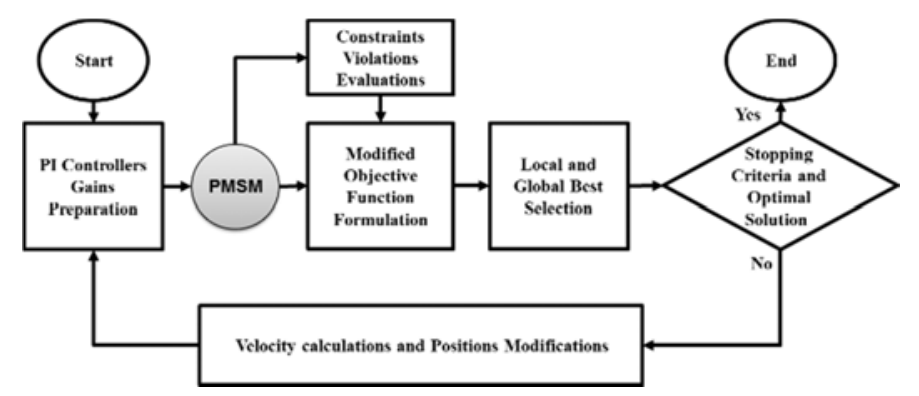

Figure 5. Schematic diagram for PSO

\section{SIMULATION RESULTS}

Matlab/Simulink software is utilized in order to evaluate the performance of the proposed drive system presented in Figure 1. The PSO algorithm written and tested using Matlab m-file. The PMSM is driven at $100 \mathrm{rad} / \mathrm{sec}$ speed while a disturbance in load is applied from 50 to $100 \mathrm{~N} . \mathrm{m}$. The system simulated with and without ripples minimization algorithm, where PSO used to attain the optimal system parameters in each test. The PSO parameters which used during optimization process listed in Table 2. The PMSM parameters and the obtained optimal filter coefficients are as illustrated in Table 3.

Table 1. PSO parameters

\begin{tabular}{cccc}
\hline Variable name & value & Variable name & value \\
\hline Population size & 10 & Max. iterations & 1000 \\
$C_{1}$ & 1.5 & $Z_{\max }$ & 0.95 \\
$C_{2}$ & 1.5 & $Z_{\min }$ & 0.4 \\
$\chi$ & 1 & No. of constrains & 2 \\
\hline
\end{tabular}

Table 2. PMSM parameters and optimal filter coefficients

\begin{tabular}{cccc}
\hline \multicolumn{2}{c}{ Filter coefficients } & \multicolumn{2}{c}{ Motor parameters } \\
\hline$a_{0}^{1}, a_{0}^{2}$ & $0.07,0.01$ & $\mathrm{R}(\mathrm{ohm})$ & 0.0068 \\
$a_{1}^{1}, a_{1}^{2}$ & $0.66,0.2$ & $\mathrm{Ld}(\mathrm{mH})$ & 0.482 \\
$a_{2}^{1}, a_{2}^{2}$ & $0.25,0.22$ & $\mathrm{Lq}(\mathrm{mH})$ & 0.482 \\
$b_{1}^{1}, b_{1}^{2}$ & $-0.51,-0.22$ & $\mathrm{P}($ poles $)$ & 4 \\
$b_{2}^{1}, b_{2}^{2}$ & $-0.04,-0.25$ & $\mathrm{~J}\left(\mathrm{~kg}-\mathrm{m}^{2}\right)$ & 0.0015 \\
& & $\mathrm{Ym}(\mathrm{Wb})$ & 0.1413 \\
\hline
\end{tabular}

Figure 6 and Figure 7 present the performances of the drive system without and with filter respectively. Figure 6(a) and Figure 7(a) show the speed response where speed reference is set at $100 \mathrm{rad} / \mathrm{sec}$. Figure 6(b) and Figure 7(b) show the stator flux response where the flux reference is set at $0.1413 \mathrm{~Wb}$. Figures 6(c) and 7(c) illustrate torque responses where the load torque changed from 50 to $100 \mathrm{Nm}$ at $\mathrm{t}=0.5$ sec (partially loaded). Figure 6(d) and Figure 7(d) show the three-phase current.

Figure 6 shows a very fast response during starting and load step change with approximately zero steady state error where the flux and torque performance contain considerable ripples and total harmonic distortion (THD) in current.

The drive system performance including filter effect is depicted in Figure 7 at the same operating conditions when the system operates without filter. The torque ripples reduced from 3.86 to 1.038 N.m and the flux ripples reduced from $2.9 * 10-3$ Web to $9.4 * 10-4$ Web when using the proposed ripple minimization algorithm which is within specified limit of $5 * 10-3$ Web during optimization, while THD in current waveform is reduced from $12 \%$ to $4.8 \%$. 


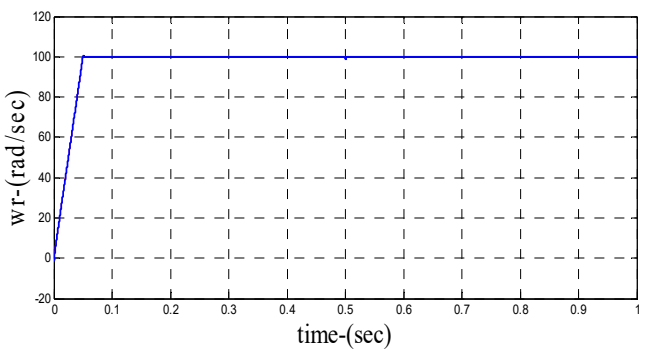

(a)

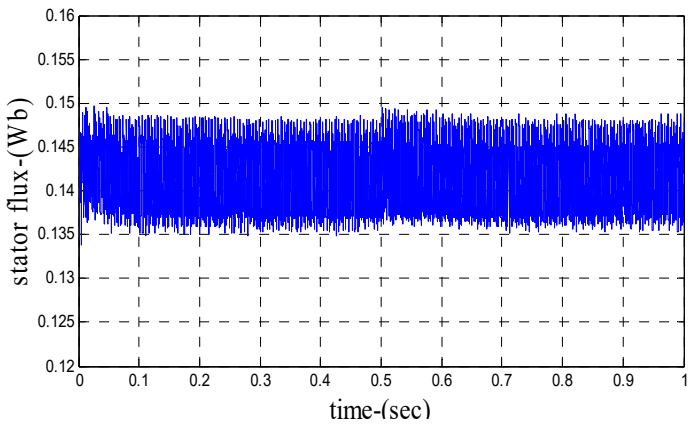

(c)

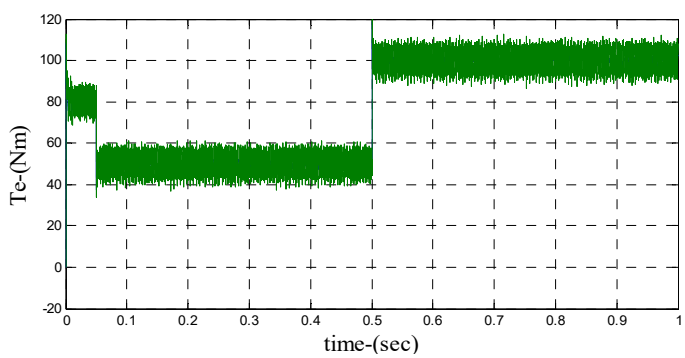

(b)

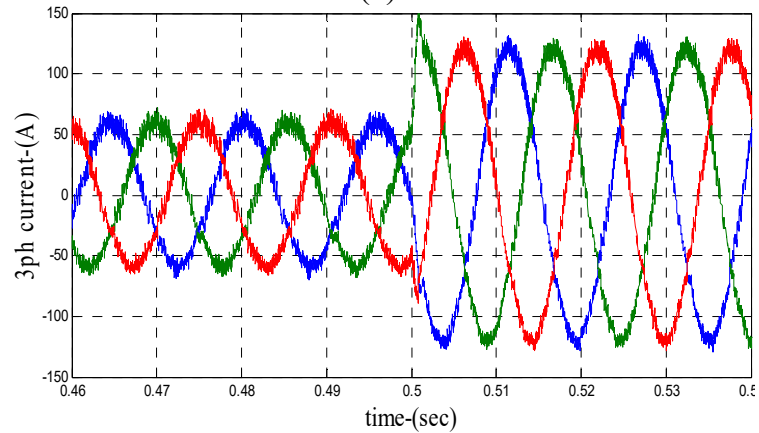

(d)

Figure 6. Drive response without filter

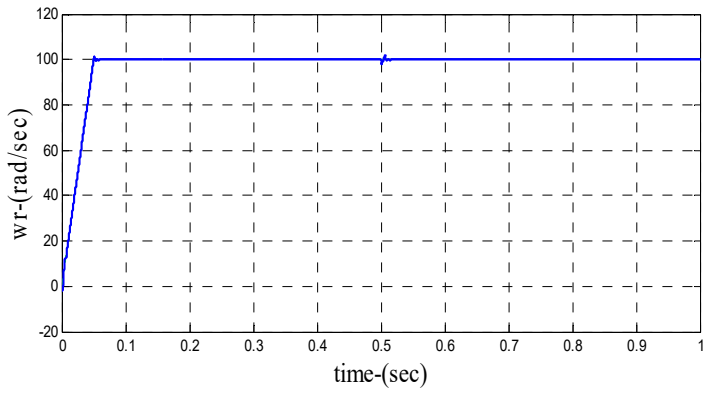

(a)

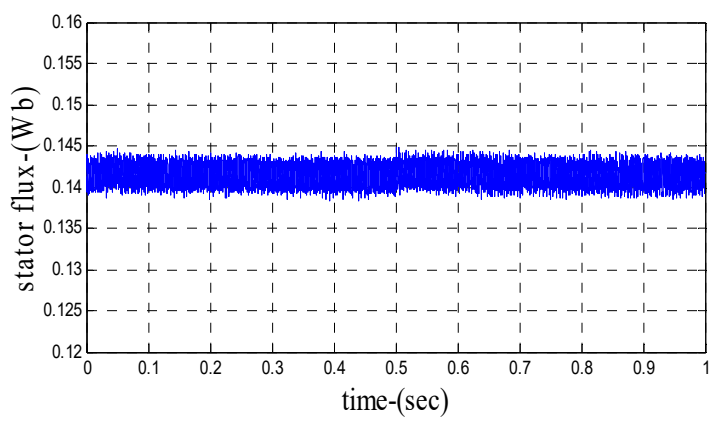

(c)

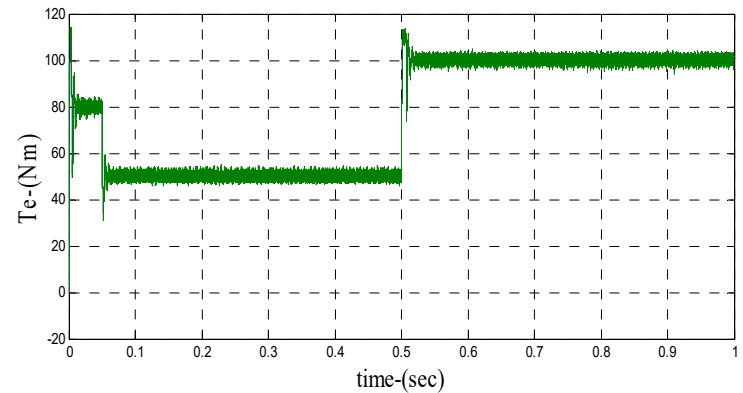

(b)

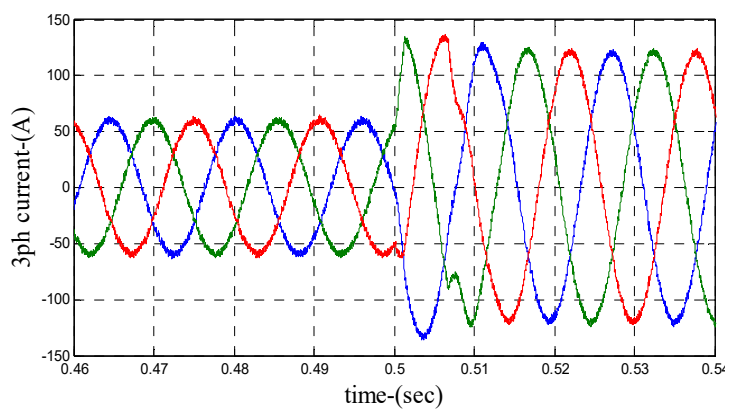

(d)

Figure 7. Drive response filter 


\section{CONCLUSION}

This paper presents the application of adaptive IIR filter integrated with FLC as a speed controller to minimize the torque and flux ripples which coming from FLC. The ripple minimization algorithm used to update the filter coefficients on line based on feedback signal from the torque ripples. The optimal coefficients of IIR and controller parameters have been estimated by using PSO to minimize the torque and flux ripples. The system behavior with and without the proposed ripple reduction method has been tested by simulation. The simulation results show a reduction in the ripples of the torque and stator flux has been attained by $73 \%$ and $67 \%$ respectively with respect to the system performance without ripple reduction algorithm. However, the total harmonic distortion in the current waveform has been reduced by $60 \%$.

\section{ACKNOWLEDGEMENTS}

This work is a part of the research project number 5853-438-1 which supported by Scientific Research Deanship, Taif University, KSA.

\section{REFERENCES}

[1] Muldi Yuhendri, Ahyanuardi, Aswardi, "Direct Torque Control Strategy of PMSM Employing Ultra Sparse Matrix Converter," International Journal of Power Electronics and Drive System (IJPEDS), Vol. 9, No. 1, pp. 64-72, March 2018

[2] M. Depenbrock, "Direct self-control (DSC) of inverter-fed induction machine", IEEE Transactions on Power Electronics vol. 3, no. 4, pp. 420-429, Oct. 1988.

[3] X. Zhang and G. H. B. Foo, "A Constant Switching Frequency-Based Direct Torque Control Method for Interior Permanent-Magnet Synchronous Motor Drives," in IEEE/ASME Transactions on Mechatronics, vol. 21, no. 3, pp. 1445-1456, June 2016.

[4] X. Wang, Z. Wang, M. Cheng and Y. Hu, "Remedial Strategies of T-NPC Three-Level Asymmetric Six-Phase PMSM Drives Based on SVM-DTC," in IEEE Transactions on Industrial Electronics, vol. 64, no. 9, pp. 6841-6853, Sept. 2017.

[5] J. Wanjiku, M. A. Khan, P. S. Barendse and P. Pillay, "Influence of Slot Openings and Tooth Profile on Cogging Torque in Axial-Flux PM Machines," in IEEE Transactions on Industrial Electronics, vol. 62, no. 12, pp. 7578-7589, Dec. 2015.

[6] R. Islam, I. Husain, A. Fardoun and K. McLaughlin, "Permanent Magnet Synchronous Motor Magnet Designs with Skewing for Torque Ripple and Cogging Torque Reduction," 2007 IEEE Industry Applications Annual Meeting, New Orleans, LA, pp. 1552-1559, 2007.

[7] Shinohara, Y. Inoue, S. Morimoto and M. Sanada, "Maximum Torque Per Ampere Control in Stator Flux Linkage Synchronous Frame for DTC-Based PMSM Drives Without Using q-Axis Inductance," in IEEE Transactions on Industry Applications, vol. 53, no. 4, pp. 3663-3671, July-Aug. 2017.

[8] S. Wahsh, Y. Ahmed and M. Abd El Aziz, "Intelligent control of PMSM drives using type-2 fuzzy," 2012 International Conference on Renewable Energy Research and Applications (ICRERA), Nagasaki, pp. 1-6, 2012.

[9] M. N. Uddin, "An adaptive filter based torque ripple minimization of a fuzzy logic controller for speed control of a PM synchronous motor," Fourtieth IAS Annual Meeting. Conference Record of the 2005 Industry Applications Conference, vol. 2., Kowloon, Hong Kong, pp. 1300-1306, 2005.

[10] G. Feng, C. Lai and N. C. Kar, "A Closed-Loop Fuzzy-Logic-Based Current Controller for PMSM Torque Ripple Minimization Using the Magnitude of Speed Harmonic as the Feedback Control Signal," in IEEE Transactions on Industrial Electronics, vol. 64, no. 4, pp. 2642-2653, April 2017.

[11] Y. Zhang and J. Zhu, "A Novel Duty Cycle Control Strategy to Reduce Both Torque and Flux Ripples for DTC of Permanent Magnet Synchronous Motor Drives With Switching Frequency Reduction," in IEEE Transactions on Power Electronics, vol. 26, no. 10, pp. 3055-3067, Oct. 2011.

[12] Y. Zhang, J. Zhu, W. Xu and Y. Guo, "A Simple Method to Reduce Torque Ripple in Direct Torque-Controlled Permanent-Magnet Synchronous Motor by Using Vectors with Variable Amplitude and Angle," in IEEE Transactions on Industrial Electronics, vol. 58, no. 7, pp. 2848-2859, July 2011.

[13] M. H. Vafaie, B. MirzaeianDehkordi, P. Moallem and A. Kiyoumarsi, "Minimizing Torque and Flux Ripples and Improving Dynamic Response of PMSM Using a Voltage Vector with Optimal Parameters," in IEEE Transactions on Industrial Electronics, vol. 63, no. 6, pp. 3876-3888, June 2016.

[14] C. Lai, G. Feng, K. L. V. Iyer, K. Mukherjee and N. C. Kar, "Genetic Algorithm-Based Current Optimization for Torque Ripple Reduction of Interior PMSMs," in IEEE Transactions on Industry Applications, vol. 53, no. 5, pp. 4493-4503, Sept.-Oct. 2017.

[15] K. Chikh, A. Saad, M. Khafallah, D. Yousfi, F.Z. Tahiri, M. Hasoun, " A Constant Switching Frequency DTC for PMSM Using Low Switching Losses SVM-An Experimental Result," International Journal of Power Electronics and Drive System (IJPEDS), Vol. 8, No. 2, pp. 558-583, June 2017

[16] C. Xia, B. Ji and Y. Yan, "Smooth Speed Control for Low-Speed High-Torque Permanent-Magnet Synchronous Motor Using Proportional-Integral-Resonant Controller," in IEEE Transactions on Industrial Electronics, vol. 62, no. 4, pp. 2123-2134, April 2015.

Int J Pow Elec \& Dri Syst, Vol. 10, No. 1, March 2019 : 48 - 57 
[17] A Sudhakar, M Vijaya Kumar, " Neural Network Controllers in Direct Torque Controlled Synchronous Motor," International Journal of Power Electronics and Drive System (IJPEDS), Vol.3, No.3, pp. 311-320, September 2013.

[18] Yen-Shin Lai and Juo-Chiun Lin," New hybrid fuzzy controller for direct torque control induction motor drives," in IEEE Transactions on Power Electronics, vol. 18, no. 5, pp. 1211-1219, September. 2003.

[19] M. N. Uddin, "An Adaptive-Filter-Based Torque-Ripple Minimization of a Fuzzy-Logic Controller for Speed Control of IPM Motor Drives," in IEEE Transactions on Industry Applications, vol. 47, no. 1, pp. 350-358, January-February 2011.

[20] S. WAHSH, M. ABDELAZIZ and Y. AHMED: "Fuzzy Logic Control of Direct Torque Control PMSM Drives Using Space Vector Techniques," in SCIS\&ISIS Conference, Tokyo, JAPAN, pp766-771, 20-24 September 2006.

[21] Hoballah and I. Erlich, "PSO-ANN approach for transient stability constrained economic power generation," IEEE Bucharest Power Tech, Bucharest, pp. 1-6, 2009.

[22] K. D. Hoang, Y. Ren, Z. Q. Zhu and M. Foster, "Modified switching-table strategy for reduction of current harmonics in direct torque controlled dual-three-phase permanent magnet synchronous machine drives," in IET Electric Power Applications, vol. 9, no. 1, pp. 10-19, 2015.

[23] Y. Zhang and J. Zhu, "Direct Torque Control of Permanent Magnet Synchronous Motor with Reduced Torque Ripple and Commutation Frequency," in IEEE Transactions on Power Electronics, vol. 26, no. 1, pp. 235-248, Jan. 2011.

[24] Hoballah and I. Erlich, "Online market-based rescheduling strategy to enhance power system stability," in IET Generation, Transmission \& Distribution, vol. 6, no. 1, pp. 30-38, January 2012.

\section{BIOGRAPHIES OF AUTHORS}

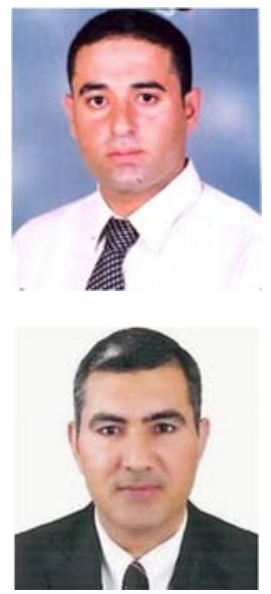

Dr. Yasser Ahmed obtained his B.Sc. from Tanta University, Egypt, Faculty of Engineering, Electrical Power and Machines department at 1999, MSc and Ph.D. from Cairo University, Egypt, Faculty of Engineering at 2006 and 2014. He works at Electronic Research Institute (ERI), Egypt, Power Electronics and Energy Conversion department since 2001. His major interests are electric drives, electric and hybrid electric vehicles, modeling and simulation of electrical systems.

Dr. Ayman Hoballah received the B.Sc. and M.Sc. degrees in Electrical Engineering from Tanta University, Egypt in 1996 and 2003. Since 1998, he has been with the Electrical Power and Machines department, Faculty of Engineering, University of Tanta/Egypt. He completed his Ph.D. in electrical engineering department from the university Duisburg- Essen, Germany in 2011. His Ph.D. thesis focuses on the power system dynamic stability. Enhancement utilizing artificial intelligent techniques. His current reach interests include power system stability, DGs, smart grid, grounding systems and optimization techniques. 